Check for updates

Cite this: RSC Adv., 2017, 7, 22892

\title{
High-performance removal of methyl mercaptan by nitrogen-rich coconut shell activated carbon
}

\author{
Qiang Liu, D Ming Ke, ${ }^{*}$ Feng Liu, Pei Yu, Haiqiang Hu and Changchun Li
}

A series of nitrogen-doped coconut shell activated carbon catalysts were prepared by urea or melamine impregnation followed by heat treatment and used for the removal of methyl mercaptan $\left(\mathrm{CH}_{3} \mathrm{SH}\right)$. The physical and chemical properties of the nitrogen-doped coconut shell activated carbons were evaluated by nitrogen adsorption/desorption, scanning electron microscopy, X-ray photoelectron spectroscopy, elemental analysis, Boehm titration, and thermal analysis. The results show that $\mathrm{CH}_{3} \mathrm{SH}$ capacity depends on the nitrogen content. Further research indicates that pyridinic nitrogen and quaternary nitrogen are the active sites. Due to the metal-free property of the nitrogen-rich coconut shell activated carbon, the regeneration process can be easily performed and dimethyl disulfide $\left(\mathrm{CH}_{3} \mathrm{SSCH}_{3}\right)$ can be recovered as the main product. Our study indicates that there is a promising prospect for nitrogen-rich coconut shell activated carbon for $\mathrm{CH}_{3} \mathrm{SH}$ removal because of its high capacity, mild conditions, and easy regeneration.

\section{Introduction}

As a colorless, polar, and volatile organic sulfur compound, methyl mercaptan (methanethiol, $\mathrm{CH}_{3} \mathrm{SH}$ ) is well known for its disagreeable odour. ${ }^{\mathbf{1 , 2}}$ It exists widely in petroleum gas, coal gas, and natural gas, and can be emitted from many agricultural and chemical processes. When released into the atmosphere, $\mathrm{CH}_{3} \mathrm{SH}$ can contribute to the formation of sulfate particles, which potentially change the Earth's radiation balance and lead to acid rain..$^{3,4}$ In addition to causing environmental pollution, $\mathrm{CH}_{3} \mathrm{SH}$ can also cause problems in the chemical industry. Sulfur is a well-known poison for many industrial catalysts because of its ability to adsorb strongly onto metal or metal oxide surfaces. For instance, the catalytic activities of modern bi-metallic reforming catalysts decrease significantly in the presence of as little as 1 ppm of sulfur. ${ }^{5}$ Furthermore, sulfur corrodes pipelines and reactors. Hence, the removal of $\mathrm{CH}_{3} \mathrm{SH}$ from feedstock gas is extremely important.

Several technologies have been investigated to remove $\mathrm{CH}_{3} \mathrm{SH}$ from gas, including adsorption, catalytic incineration, catalytic adsorption/oxidation, decomposition, and photocatalytic oxidation. ${ }^{6-10}$ Among these technologies, catalytic adsorption/oxidation is identified as a promising method because of its high sulfur capacity, mild conditions, and easy regeneration.

Activated carbon has been widely used for the purification of sulfur-containing gas because of its highly developed porous structure, unique surface chemistry, and potential biocompatibility. $\mathrm{CH}_{3} \mathrm{SH}$ can be easily oxidized to dimethyl disulfide $\left(\mathrm{CH}_{3} \mathrm{SSCH}_{3}\right)$,

State Key Laboratory of Heavy Oil Processing, China University of Petroleum, Beijing 102249, P. R. China. E-mail: keming@cup.edu.cn; Tel: +86108973 3372 which is easily stored in the activated carbon pores because of its large molecular size and high boiling point. ${ }^{11-13}$ The sulfur capacity of activated carbon is affected by both the porosity and surface chemistry. Micropores are favorable for the adsorption of methyl mercaptan. ${ }^{\mathbf{1 1 4}}$ After methyl mercaptan is adsorbed in the micropores, it will be oxidized to dimethyl disulfide. Furthermore, the sulfur capacity of activated carbon can be enhanced by introducing heteroatoms, such as nitrogen and oxygen, bonded to the carbon matrix and by impregnating the metal oxides as the oxidation centers. $^{\text {14-19 }}$

At present, nitrogen-containing carbon materials, which can be derived from the carbonization of nitrogen-containing precursors or the post-treatment of carbon products with nitrogen-rich compounds, are attracting much attention because of their unique properties. ${ }^{\mathbf{2 0 - 2 4}}$ Specifically, nitrogendoped carbon materials can be used for the removal of small molecular toxic gases, such as $\mathrm{CH}_{3} \mathrm{SH}, \mathrm{NO}_{2}$, and $\mathrm{H}_{2} \mathrm{~S}$. ${ }^{\mathbf{1 4 , 2 4 , 2 5}}$ However, most research focuses on coal-based activated carbons. Little systematic attention has been devoted to study the removal of $\mathrm{CH}_{3} \mathrm{SH}$ by activated carbon that contains nitrogen groups. Coconut shell activated carbons, which usually have a more porous structure than coal-based activated carbons, could be effective supports for the adsorption of $\mathrm{CH}_{3} \mathrm{SH}$. Herein, we investigate the effect of nitrogen functionalities on the removal of $\mathrm{CH}_{3} \mathrm{SH}$ by evaluating a series of nitrogen-doped coconut shell activated carbons modified with urea and melamine. The relationships between the $\mathrm{CH}_{3} \mathrm{SH}$ capacity and the contents of pyridinic nitrogen and quaternary nitrogen were verified. The physical and chemical properties of the nitrogen-doped coconut shell activated carbons were evaluated by nitrogen adsorption/desorption, scanning electron microscopy, X-ray photoelectron spectroscopy, elemental 
analysis, and Boehm titration. Thermal analysis and gas chromatography-mass spectrometry were used to study the oxidation product stored in the carbon. Moreover, regeneration tests were performed. Finally, a possible overall mechanism is proposed to explain the adsorption/oxidation of $\mathrm{CH}_{3} \mathrm{SH}$ over the nitrogen-rich coconut shell activated carbon.

\section{Materials and methods}

\subsection{Preparation of catalysts}

A commercial coconut shell activated carbon was provided by Fujian Xinsen New Technology Co, Ltd. The initial material was ground, sieved to 10-20 mesh, washed with deionized water, and dried at $115{ }^{\circ} \mathrm{C}$ for $12 \mathrm{~h}$ in an oven. The initial activated carbon was designated AC. Then, the AC was oxidized with 30 $\mathrm{wt} \% \mathrm{HNO}_{3}$ at $60{ }^{\circ} \mathrm{C}$ and stirred for $3 \mathrm{~h}$. Subsequently, the oxidized activated carbon was filtered and rinsed with deionized water to a neutral $\mathrm{pH}$ and dried at $115{ }^{\circ} \mathrm{C}$ for $12 \mathrm{~h}$. This oxidized activated carbon was designated ACO. To introduce nitrogen groups, AC and ACO (12 g) were first impregnated with urea or melamine ( $8 \mathrm{~g}$ of urea or melamine in $40 \mathrm{~mL}$ of ethanol) at $25^{\circ} \mathrm{C}$ for $5 \mathrm{~h}$ with vigorous agitation. Then, the mixture was heated to promote ethanol evaporation, and the carbon was dried at $115{ }^{\circ} \mathrm{C}$. Secondly, the impregnated activated carbon was heated in nitrogen from room temperature to $950{ }^{\circ} \mathrm{C}$ at $10{ }^{\circ} \mathrm{C} \mathrm{min}{ }^{-1}$ and calcined for $30 \mathrm{~min}$. Finally, the activated carbons were rinsed using excess boiling water to remove any water-soluble decomposition products and heated at $115{ }^{\circ} \mathrm{C}$ for $12 \mathrm{~h}$. The nitrogen-doped activated carbons were designated ACU, ACOU, $\mathrm{ACM}$, and ACOM, where $\mathrm{U}$ and $\mathrm{M}$ represent urea and melamine, respectively. For example, ACOU represents AC that was preoxidized, impregnated with urea, and calcined at $950{ }^{\circ} \mathrm{C}$.

\subsection{Catalysts characterization}

$\mathrm{N}_{2}$ adsorption-desorption isotherms were measured at $-196{ }^{\circ} \mathrm{C}$ using an Autosorb-iQ (Quantachrome Instruments) surface area analyzer. Before the measurements, the samples were heated and outgassed at $120{ }^{\circ} \mathrm{C}$ overnight. The Brunauer-EmmettTeller (BET) method was used to calculate the specific surface area. The total pore volume was obtained according to the adsorbed $\mathrm{N}_{2}$ volume at a relative pressure of approximately 0.99 . The micropore volumes and pore size distributions were calculated using nonlocal density functional theory. ${ }^{26,27}$ The surface morphologies of the activated carbons were observed using field emission scanning electron microscopy (Quanta $200 \mathrm{~F}$ ) with an accelerating voltage of $20 \mathrm{kV}$. The elemental analyses $(\mathrm{C}, \mathrm{H}, \mathrm{N})$ of the original and nitrogen-doped activated carbons were performed using a Euro Vector EA3000 elemental analyzer. X-ray photoelectron spectroscopy (XPS) measurements were recorded using a Thermo ESCALAB 250XI spectrometer with $\mathrm{Al} \mathrm{K} \alpha$ radiation. The standard binding energy of $\mathrm{C}$ 1s (284.4 eV) was adopted as an internal reference. The results were analyzed using the XPSPEAK 4.1 software. Carbon powder $(0.4$ g) was mixed with $20 \mathrm{~mL}$ of water, and the mixture was stirred for $12 \mathrm{~h}$ at room temperature. The $\mathrm{pH}$ of the suspension liquid was used to approximate the $\mathrm{pH}$ of the carbon surface.
Meanwhile, pHE was used to represent the $\mathrm{pH}$ of the exhausted samples. Methanol $(1 \mathrm{~mL})$ and carbon $(0.6 \mathrm{~mL})$ were mixed in a flask and warmed at $60{ }^{\circ} \mathrm{C}$ for $1 \mathrm{~h}$. Then, the suspension liquid was analyzed by gas chromatography-mass spectrometry (GC/MS) experiments using a Thermo Fisher DSQ gas chromatograph/mass spectrometer. GC separation was operated on a HP-5 MS quartz tube capillary column (dimensions: 30 $\mathrm{m} \times 0.25 \mathrm{~mm} \times 0.25 \mu \mathrm{m})$. The column temperature was increased from $50{ }^{\circ} \mathrm{C}$ to $310^{\circ} \mathrm{C}\left(5^{\circ} \mathrm{C} \mathrm{min}{ }^{-1}\right)$ and maintained for $25 \mathrm{~min}$. An unrestricted library search was used to analyze the results. The carbon sample $(0.5 \mathrm{~g})$ was mixed with $25 \mathrm{~mL}$ of 0.05 $\mathrm{N}$ solutions of $\mathrm{HCl}$ and $\mathrm{NaOH}$. The flasks were sealed and shaken for $24 \mathrm{~h}$. Then, $5 \mathrm{~mL}$ of each filtrate was taken and the excessive acid or base was equilibrated with sodium hydroxide or hydrochloric acid. The numbers of total acidic sites were obtained according to the hypothesis that $\mathrm{NaOH}$ neutralizes all types of acidic sites, including carboxyl, lactonic, and phenolic groups. The number of basic sites was calculated based on the amount of $\mathrm{HCl}$ that was consumed by the carbon sample.

\subsection{Catalyst activity evaluation}

The adsorption capacity of $\mathrm{CH}_{3} \mathrm{SH}$ was evaluated under atmospheric pressure in a fixed bed quartz reactor. Prior to the test, the activated carbons were humidified with moist air (relative humidity: $80 \%, 25{ }^{\circ} \mathrm{C}$ ) for $40 \mathrm{~min}$. Then, the moist air with $0.2 \%$ $\mathrm{CH}_{3} \mathrm{SH}(2000 \mathrm{ppm}$ ) was passed through the reactor bed. The relative humidity was controlled by a saturator system. In all tests, the overall gas hourly space velocity was standardized at $7500 \mathrm{~h}^{-1}$ by adjusting the calibrated mass flow controllers. The reactor temperature was maintained at $25{ }^{\circ} \mathrm{C}$ using a water bath with an accuracy of $\pm 0.1^{\circ} \mathrm{C}$. The concentration of $\mathrm{CH}_{3} \mathrm{SH}$ in the gaseous effluent was analyzed by a GC-6890 sulfur phosphorus micro-analyzer integrated with a pulsed flame photometric detector. After the adsorption test, the exhausted samples were designated with the letter E. To study the roles of water and oxygen in the removal of $\mathrm{CH}_{3} \mathrm{SH}$, desulfurization experiments were also tested using dry air and dry nitrogen as carrier gases. AC and ACOM samples were performed under different conditions and are designated as ACA, ACN, ACOMA, and ACOMN, where $\mathrm{A}$ and $\mathrm{N}$ represent dry air and dry nitrogen, respectively.

The $\mathrm{CH}_{3} \mathrm{SH}$ adsorption capacity was determined by the accumulated amount of $\mathrm{CH}_{3} \mathrm{SH}$ adsorbed when the $\mathrm{CH}_{3} \mathrm{SH}$ adsorption efficiency dropped to $98 \%$. After the breakthrough test, the $\mathrm{CH}_{3} \mathrm{SH}$ adsorption capacity was calculated by integration of the area of the $\mathrm{CH}_{3} \mathrm{SH}$ breakthrough curves as follows:

$$
\begin{gathered}
\alpha \equiv \frac{C_{\text {inlet }}-C_{\text {outlet }}}{C_{\text {inlet }}} \times 100 \% \\
S \equiv \frac{Q C_{\text {inlet }} \int_{0}^{t} \alpha \mathrm{d} t}{m}
\end{gathered}
$$

where $\alpha$ is the $\mathrm{CH}_{3} \mathrm{SH}$ removal efficiency, $C_{\text {inlet }}$ is the entrance concentration $\left(\mathrm{mg} \mathrm{m}^{-3}\right), C_{\text {outlet }}$ is the outlet concentration $(\mathrm{mg}$ $\left.\mathrm{m}^{-3}\right), Q$ is the gas flow $\left(\mathrm{m}^{3} \mathrm{~min}^{-1}\right), t$ is the adsorption time ( $\mathrm{min}$ ), $m$ is the catalyst quality ( $\mathrm{g}$ ), and $S$ is the $\mathrm{CH}_{3} \mathrm{SH}$ adsorption capacity $\left(\mathrm{mg} \mathrm{g}^{-1}\right)$. 


\subsection{Regeneration of exhausted activated carbons}

The exhausted activated carbon $(6 \mathrm{~mL})$ was mixed with $300 \mathrm{~mL}$ of ethanol for $5 \mathrm{~h}$ at $50{ }^{\circ} \mathrm{C}$ and then filtered. Three cycles were performed, and then the activated carbon was heated at $500{ }^{\circ} \mathrm{C}$ for $0.5 \mathrm{~h}$ in a nitrogen atmosphere. The regenerated samples are designated with a number that represents the regeneration time.

\section{Results and discussion}

\subsection{Texture and chemical properties of the nitrogen-doped coconut shell activated carbon}

As the reactive molecules diffuse into the pores and the oxidation products are stored therein, the porosity of the activated carbon is crucial to the $\mathrm{CH}_{3} \mathrm{SH}$ adsorption/oxidation process. The $\mathrm{N}_{2}$ adsorption isotherms and pore size distribution curves of the activated carbons are presented in Fig. 1, and the calculated structural parameters are summarized in Table 1. In Fig. 1a, all samples share a similar isotherm shape and can be classified as type I, which indicates a microporous structure. Moreover, all samples have hysteresis loops at high relative pressures, verifying the presence of mesopores. Similar distribution patterns are presented in Fig. 1b. The pores of all samples are mainly distributed in the micropore range, and partly in the mesopore range. The pore sizes of all samples are mainly below $10 \mathrm{~nm}$. From Table 1, it can be concluded that
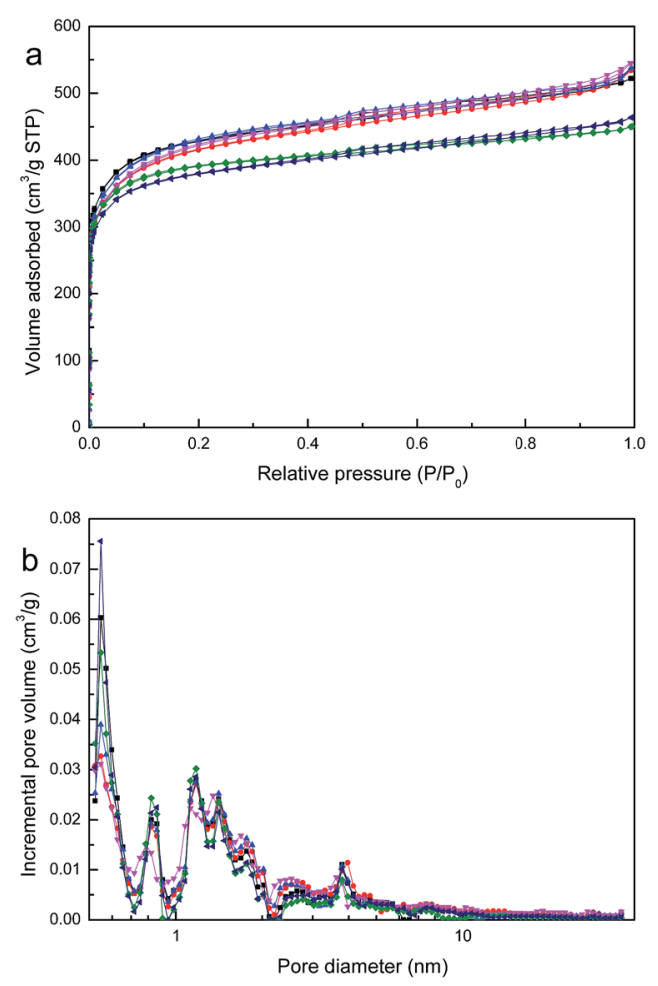

-AC; -ACO; - ACU; -ACOU; -ACM; -ACOM

Fig. $1 \mathrm{~N}_{2}$ adsorption/desorption isotherms (a) and pore size distribution curves (b) of the samples.
Table 1 Structural parameters of samples calculated from the nitrogen adsorption isotherms

\begin{tabular}{llllll}
\hline Sample & $\begin{array}{l}S_{\text {BET }} \\
\left(\mathrm{m}^{2} \mathrm{~g}^{-1}\right)\end{array}$ & $\begin{array}{l}V_{<1 \mathrm{~nm}} \\
\left(\mathrm{~cm}^{3} \mathrm{~g}^{-1}\right)\end{array}$ & $\begin{array}{l}V_{\text {mic }} \\
\left(\mathrm{cm}^{3} \mathrm{~g}^{-1}\right)\end{array}$ & $\begin{array}{l}V_{\mathrm{t}} \\
\left(\mathrm{cm}^{3} \mathrm{~g}^{-1}\right)\end{array}$ & $V_{\text {mic }} / V_{\mathrm{t}}$ \\
\hline AC & 1508 & 0.329 & 0.571 & 0.807 & 0.708 \\
ACO & 1476 & 0.297 & 0.546 & 0.826 & 0.661 \\
ACU & 1501 & 0.303 & 0.568 & 0.832 & 0.683 \\
ACOU & 1433 & 0.285 & 0.543 & 0.844 & 0.643 \\
ACM & 1397 & 0.313 & 0.534 & 0.697 & 0.766 \\
ACOM & 1358 & 0.299 & 0.509 & 0.718 & 0.709 \\
\hline
\end{tabular}

modifications of activated carbons affect the surface area and pore volumes.

The AC sample has a BET surface area of $1508 \mathrm{~m}^{2} \mathrm{~g}^{-1}$, a micropore volume of $0.571 \mathrm{~cm}^{3} \mathrm{~g}^{-1}$, and a total pore volume of $0.807 \mathrm{~cm}^{3} \mathrm{~g}^{-1}$. Nitric acid oxidation increases the total pore volume and decreases the micropore volume and BET surface area. These observations indicate the erosion and pore-widening effects of nitric acid treatment, which are consistent with previous reports. ${ }^{28-30}$ A small decrease of the micropore volume and a small increase of the total pore volume are found for the urea-modified ACU and ACOU samples. In addition, the micropore and total pore volumes of the melamine-modified ACM and ACOM samples show obvious decreasing trends, which are probably due to that the introduced nitrogen-containing species create steric hindrances and partially prevent the access of nitrogen molecules into the micropores. ${ }^{31,32}$

The SEM micrographs of the original activated carbon and modified activated carbons are illustrated in Fig. 2. An abundant porous structure is observed on the activated carbon surface, which favors $\mathrm{CH}_{3} \mathrm{SH}$ adsorption. After nitric acid oxidation, little difference is found for the surface morphology of AC and ACO, except for some pore widening and the cleaner surface of ACO, which is due to the erosion and cleansing effect of nitric acid..$^{33-35}$ Different nitrogen precursors provide different impacts on the surface morphologies. The surface morphologies of ACU and ACOU are similar to those of AC and ACO, but obvious pore blockages are found on the surfaces of ACM and ACOM compared to the surfaces of AC and ACO. This indicates that the surface area and pore volume of the nitrogendoped carbons decrease with the introduction of nitrogen by melamine, which is consistent with the BET results.

The surface chemistry of activated carbon is an important aspect in the removal of $\mathrm{CH}_{3} \mathrm{SH}$. The acid-base properties of the representative samples were investigated by Boehm titration, and the results are shown in Table $2 .^{36}$ The number of acidic groups increases sharply while the number of basic groups decreases to almost zero after nitric acid oxidation. As expected, modification of the nitrogen-containing groups significantly increases the number of basic groups, especially for the preoxidized samples, which is consistent with the changes of the surface $\mathrm{pH}$ values.

Elemental analysis and XPS were conducted to investigate the nitrogen contents and species of the activated carbons. According to the results shown in Table 3, the nitrogen contents 

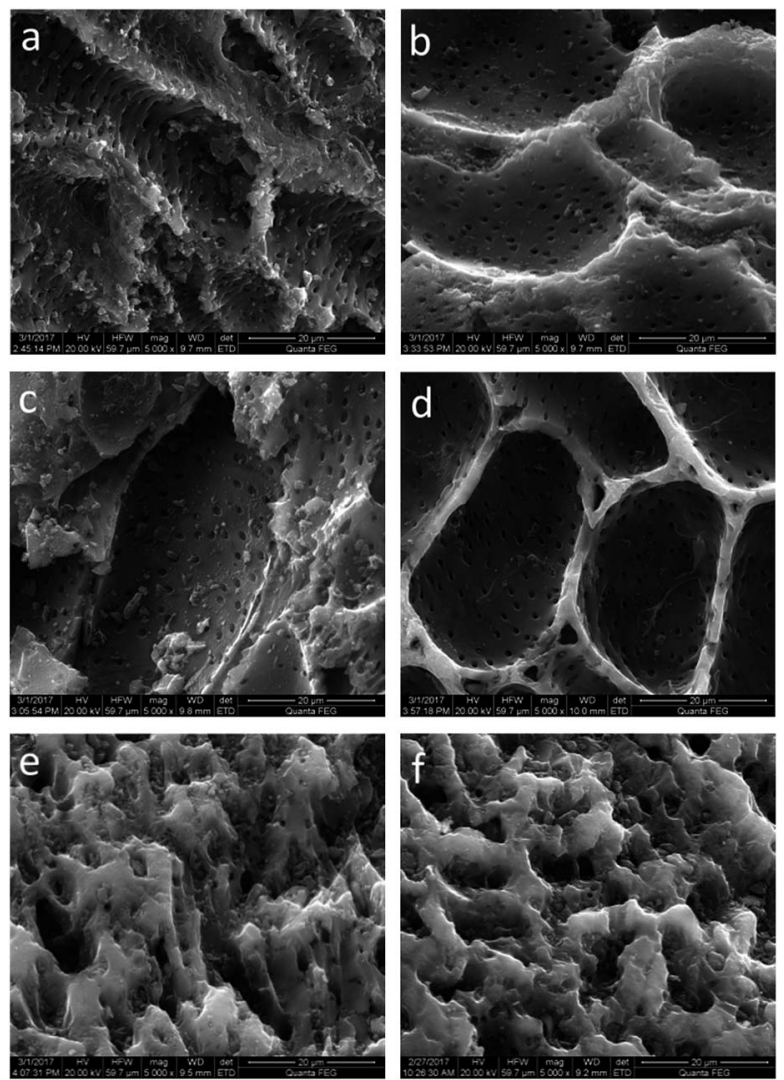

Fig. 2 SEM images of (a) AC, (b) ACO, (c) ACU, (d) ACOU, (e) ACM, and (f) ACOM.

Table 2 Results of the Boehm titration (number of surface groups) and surface $\mathrm{pH}$ values

\begin{tabular}{lllll}
\hline Sample & $\mathrm{pH}$ & $\begin{array}{l}\text { Acidic } \\
\left(\mathrm{mmol} \mathrm{g}^{-1}\right)\end{array}$ & $\begin{array}{l}\text { Basic } \\
\left(\mathrm{mmol} \mathrm{g}^{-1}\right)\end{array}$ & $\begin{array}{l}\text { All } \\
\left(\mathrm{mmol} \mathrm{g}^{-1}\right)\end{array}$ \\
\hline AC & 7.34 & 0.47 & 0.55 & 1.02 \\
ACO & 3.32 & 1.65 & 0 & 1.65 \\
ACU & 8.79 & 0.40 & 0.74 & 1.14 \\
ACOU & 8.48 & 0.39 & 0.69 & 1.08 \\
ACM & 8.94 & 0.43 & 0.96 & 1.39 \\
ACOM & 8.31 & 0.41 & 0.66 & 1.07 \\
\hline
\end{tabular}

of the samples after modification with urea and melamine can be ranked as ACU $<$ ACOU $<$ ACM $<$ ACOM. Nitric acid oxidation is conducive to introducing nitrogen groups by increasing the number of acidic groups that can react with the precursors. Furthermore, $0.55 \%$ of the nitrogen in ACO is mainly in the form of nitrate and nitric oxides, which were introduced by the nitric acid treatment. ${ }^{31}$ Moreover, compared with the ureamodified samples, the melamine-modified samples have more nitrogen, which may be because the high content of nitrogen in the melamine molecule and its conversion to melamine resins at high temperatures. ${ }^{31}$ Fig. 3 exhibits the $\mathrm{N}$ 1s XPS results of the nitrogen-doped samples. The $\mathrm{N}$ 1s spectrum is composed of four peaks at $398.7 \pm 0.3,400.3 \pm 0.2,401.4 \pm 0.3$, and $403 \pm$ $0.3 \mathrm{eV}$, which are assigned to pyridinic nitrogen ( $\mathrm{N}-6)$, pyrrolic
Table 3 Carbon, hydrogen, and nitrogen contents (\%) of the samples

\begin{tabular}{llll}
\hline Sample & $\mathrm{C}$ & $\mathrm{H}$ & $\mathrm{N}$ \\
\hline AC & 85.66 & 0.92 & 0.16 \\
ACO & 81.58 & 0.52 & 0.55 \\
ACU & 89.75 & 0.56 & 1.02 \\
ACOU & 89.02 & 0.67 & 1.43 \\
ACM & 87.63 & 0.54 & 3.52 \\
ACOM & 86.39 & 0.71 & 4.47 \\
\hline
\end{tabular}

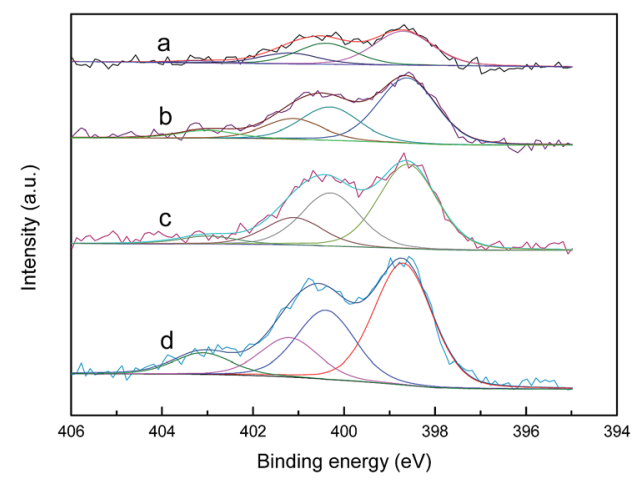

Fig. $3 \mathrm{~N}$ 1s XPS spectra of (a) ACU, (b) ACOU, (c) ACM, and (d) ACOM.

Table 4 Surface nitrogen contents and distribution of nitrogen species of the samples derived from the $N$ 1s spectra

\begin{tabular}{llllll}
\hline & & \multicolumn{4}{l}{ Distributions of nitrogen species (\%) } \\
\cline { 4 - 6 } Sample & $\begin{array}{l}\text { Nitrogen } \\
\text { content (at\%) }\end{array}$ & $\mathrm{N}-6$ & $\mathrm{~N}-5$ & $\mathrm{~N}-\mathrm{Q}$ & $\mathrm{N}-\mathrm{X}$ \\
\hline ACU & 1.39 & 50.06 & 31.11 & 16.13 & 2.70 \\
ACOU & 2.52 & 51.38 & 26.33 & 16.08 & 6.21 \\
ACM & 3.45 & 48.82 & 30.83 & 15.79 & 4.56 \\
ACOM & 4.41 & 48.53 & 27.42 & 15.48 & 8.57 \\
\hline
\end{tabular}

nitrogen $(\mathrm{N}-5)$, quaternary nitrogen $(\mathrm{N}-\mathrm{Q})$, and pyridine-N-oxide (N-X), respectively. ${ }^{37-42}$ The percent contributions of surface nitrogen species are summarized in Table 4, and the dominant nitrogen species on the surface of nitrogen-doped activated carbons are pyridinic nitrogens. Nitric acid oxidation leads to higher relative contents of pyridine-N-oxide and less pyrrolic nitrogen. The reason may be that nitric acid oxidation increases the acidic groups and creates more active sites on the surface of activated carbon, which is beneficial for nitrogen incorporation into the carbon matrix in a pyridinic-like nitrogen configuration. In addition, a small amount of pyridinic nitrogen can be converted into pyridine-N-oxide. The activated carbons modified by melamine contain lower relative amounts of pyridinic nitrogen and quaternary nitrogen than the corresponding activated carbons modified by urea. However, the melamine modification provides more nitrogen. Thus, the overall contents of pyridinic nitrogen and quaternary nitrogen in the activated carbons increase when melamine is used as a precursor. 


\subsection{Desulfurization activity}

The original and nitrogen-doped activated carbons were tested for the adsorption/oxidation of $\mathrm{CH}_{3} \mathrm{SH}$, and the breakthrough curves are presented in Fig. 4. The breakthrough time changes with the introduction of nitrogen over all samples. The calculated $\mathrm{CH}_{3} \mathrm{SH}$ breakthrough capacities from the curves are presented in Table 5. The $\mathrm{CH}_{3} \mathrm{SH}$ capacity of the original activated carbon is only $161.8 \mathrm{mg} \mathrm{g}^{-1}$. However, for the nitrogen-doped samples, higher $\mathrm{CH}_{3} \mathrm{SH}$ capacities are achieved for higher quantities of nitrogen. The highest breakthrough $\mathrm{CH}_{3} \mathrm{SH}$ capacity, as high as $602.1 \mathrm{mg} \mathrm{g}^{-1}$, is achieved for the ACOM sample in which the surface nitrogen content is 4.41 at\%. This breakthrough $\mathrm{CH}_{3} \mathrm{SH}$ capacity is among the highest $\mathrm{CH}_{3} \mathrm{SH}$ capacities reported in the literature..$^{\mathbf{1 1 4}, \mathbf{1 6}}$ Thus, the introduction of nitrogen-containing species is critical to the removal of $\mathrm{CH}_{3} \mathrm{SH}$. According to the XPS results, there are four types of nitrogen functionalities after heat-treatment. As indicated in the literature, pyridinic nitrogen and quaternary nitrogen are beneficial to the oxidation of sulfur and nitrogen-containing compounds because of their strong electron transfer abilities. ${ }^{\mathbf{1 4 2 4 , 2 5}}$ The correlation between the contents of pyridinic nitrogen and quaternary nitrogen obtained from XPS results and the $\mathrm{CH}_{3} \mathrm{SH}$ capacities of the nitrogen-doped activated carbons (ACU, ACOU, ACM, and ACOM) is discussed to illustrate the effects of these two types of nitrogen species. As shown

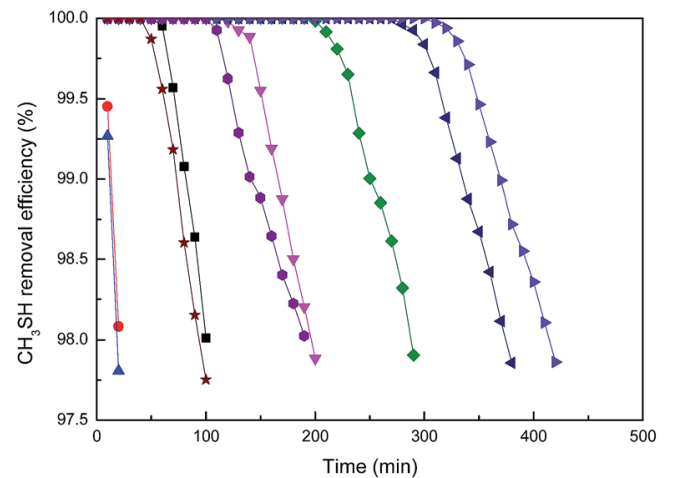

-AC; -ACA; - ACN; -ACU; -ACOU; -ACM; -ACOM; -ACOMA; -ACOMN

Fig. 4 Removal efficiency of $\mathrm{CH}_{3} \mathrm{SH}$ from the samples.

Table $5 \mathrm{pH}$ of the carbon surface, amount of preadsorbed water, and $\mathrm{CH}_{3} \mathrm{SH}$ breakthrough capacities for the samples

\begin{tabular}{lcclc}
\hline Sample & pH & pHE & $\begin{array}{l}\text { Amount of water } \\
\left(\mathrm{mg} \mathrm{g}^{-1}\right)\end{array}$ & $\begin{array}{l}\mathrm{CH}_{3} \mathrm{SH} \text { capacity } \\
\left(\mathrm{mg} \mathrm{g}^{-1}\right)\end{array}$ \\
\hline AC & 7.34 & 7.02 & 152.3 & 161.8 \\
ACA & 7.34 & 7.19 & 0 & 38.7 \\
ACN & 7.34 & 7.21 & 0 & 33.2 \\
ACU & 8.79 & 6.62 & 158.6 & 318.2 \\
ACOU & 8.48 & 5.28 & 163.4 & 465.7 \\
ACM & 8.94 & 4.76 & 154.3 & 541.3 \\
ACOM & 8.31 & 3.16 & 159.7 & 602.1 \\
ACOMA & 8.31 & 5.73 & 0 & 273.3 \\
ACOMN & 8.31 & 7.25 & 0 & 142.8
\end{tabular}

in Fig. 5, the $\mathrm{CH}_{3} \mathrm{SH}$ capacity increases with the contents of pyridinic nitrogen and quaternary nitrogen, which indicates that pyridinic nitrogen and quaternary nitrogen are responsible for $\mathrm{CH}_{3} \mathrm{SH}$ oxidation. Therefore, we conclude that the contents of pyridinic nitrogen and quaternary nitrogen are critical to implement $\mathrm{CH}_{3} \mathrm{SH}$ catalytic oxidation of activated carbon.

The experiments were also conducted under various conditions, including the absence of oxygen and water in the feed gas, to study the effects of oxygen and water on the removal of $\mathrm{CH}_{3} \mathrm{SH}$. AC and ACOM were tested and the results are summarized in Fig. 4 and Table 5 . The breakthrough $\mathrm{CH}_{3} \mathrm{SH}$ capacity of AC in the absence of moisture is at least three times smaller than that in the presence of moisture. Meanwhile, oxygen has different roles in the adsorption/oxidation of $\mathrm{CH}_{3} \mathrm{SH}$ on AC and ACOM. For AC, the breakthrough $\mathrm{CH}_{3} \mathrm{SH}$ capacity is almost the same under dry conditions, despite the presence of oxygen. Nevertheless, the breakthrough $\mathrm{CH}_{3} \mathrm{SH}$ capacity of ACOM under dry air conditions is almost twice that measured without oxygen. A thin water film can form on the carbon surface in the presence of water. ${ }^{25} \mathrm{CH}_{3} \mathrm{SH}$ dissolves into the water film and dissociates to the thiolate ion, which can be further oxidized to $\mathrm{CH}_{3} \mathrm{SSCH}_{3} \cdot{ }^{43}$ In the absence of moisture, $\mathrm{CH}_{3} \mathrm{SH}$ is first adsorbed onto the carbon surface, and then the adsorbed $\mathrm{CH}_{3} \mathrm{SH}$ can be oxidized to $\mathrm{CH}_{3} \mathrm{SSCH}_{3} \cdot{ }^{44}$ There is little difference in the $\mathrm{CH}_{3} \mathrm{SH}$ capacity of $\mathrm{AC}$ in dry air and dry nitrogen, which demonstrates the lack of participation of oxygen from the air in the removal of $\mathrm{CH}_{3} \mathrm{SH}$ due to the lack of catalytic sites. However, the larger $\mathrm{CH}_{3} \mathrm{SH}$ capacity of ACOM in dry air than that in dry nitrogen confirms the strong catalytic oxidation property of nitrogen-rich activated carbon. According to these results, we can deduce that water and oxygen are beneficial to the removal of $\mathrm{CH}_{3} \mathrm{SH}$.

\subsection{Analysis of the $\mathrm{CH}_{3} \mathrm{SH}$ oxidation product over the samples}

Thermal analysis (TA) experiments were performed to analyze the product adsorbed on the surface of the exhausted carbons, in which the weight loss at a certain temperature range could indicate the quantity of corresponding sulfur species. ${ }^{\mathbf{4 5 , 4 6}}$ Differential thermogravimetry (DTG) curves for the exhausted

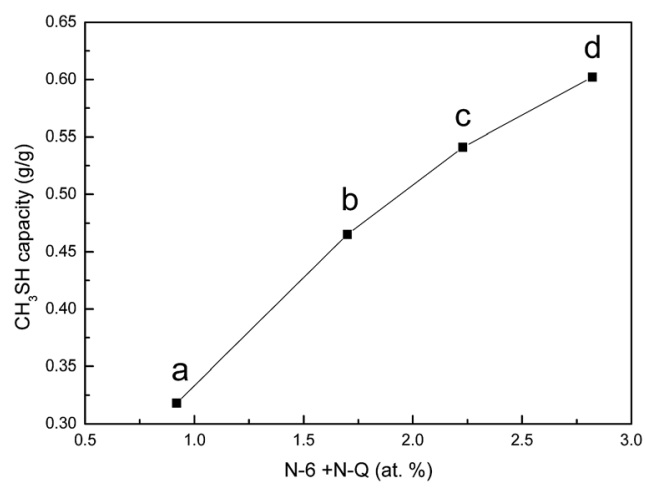

Fig. 5 Correlation between the $\mathrm{CH}_{3} \mathrm{SH}$ capacity and the amount of $\mathrm{N}$ $6+\mathrm{N}-\mathrm{Q}$ of (a) ACU, (b) ACOU, (c) ACM, and (d) ACOM. 


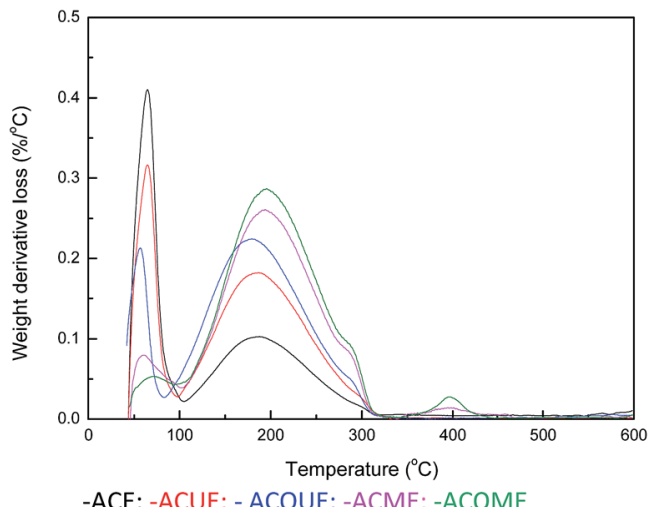

-ACE; -ACUE; - ACOUE; -ACME; -ACOME

Fig. 6 DTG curves in argon for the exhausted samples.
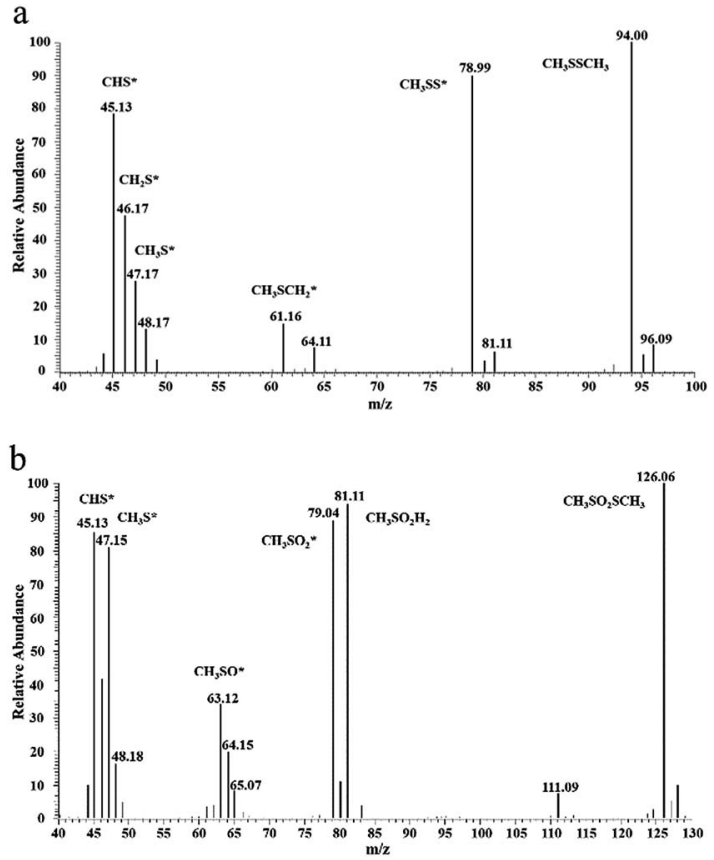

Fig. 7 GC/MS spectra for species extracted from ACOME: (a) dimethyl disulfide, (b) methyl methanethiosulfonate.

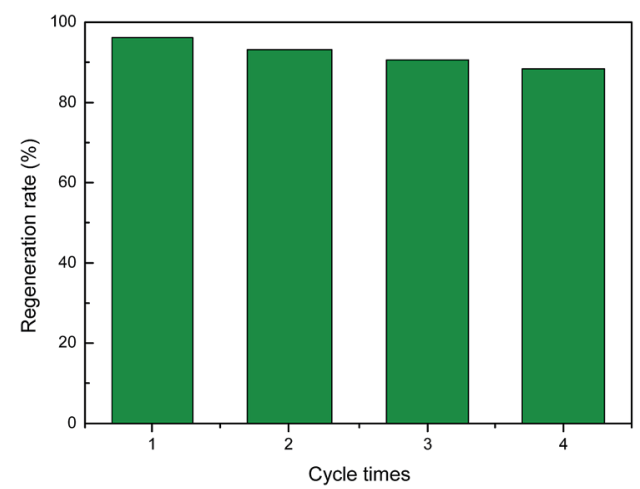

Fig. 8 Regeneration rate of ACOME. carbons are displayed in Fig. 6, and three main peaks are observed for the samples. Firstly, the peak located below $100{ }^{\circ} \mathrm{C}$ corresponds to the removal of $\mathrm{H}_{2} \mathrm{O}$. Considering the oxidation of $\mathrm{CH}_{3} \mathrm{SH}$, the second peak between $100{ }^{\circ} \mathrm{C}$ and $300{ }^{\circ} \mathrm{C}$ may represent the desorption of $\mathrm{CH}_{3} \mathrm{SSCH}_{3}$.

There is a shoulder around $290{ }^{\circ} \mathrm{C}$ for the ACOUE, ACME, and ACOME samples. Furthermore, for the ACME and ACOME samples, there is another peak between $350{ }^{\circ} \mathrm{C}$ and $450{ }^{\circ} \mathrm{C}$, and the peak area increases with respect to the content of nitrogen. Further oxidation of sulfur species is found for the nitrogendoped carbons under wet air conditions. The difference in $\mathrm{pH}$ between the fresh and exhausted carbons in Table 5 also manifests the formation of acidic oxidation products. The GC/ MS results for ACOME are shown in Fig. 7. There are two peaks that represent the presence of $\mathrm{CH}_{3} \mathrm{SSCH}_{3}$ and methyl methane thiosulfonate, according to an unrestricted library research. According to the above results, the shoulder around $290{ }^{\circ} \mathrm{C}$ may represent the removal of methyl methane thiosulfonate. The peak between $350{ }^{\circ} \mathrm{C}$ and $450{ }^{\circ} \mathrm{C}$ may represent the desorption of a deeper oxidation product, likely methanesulfonic acid. In view of the highest breakthrough $\mathrm{CH}_{3} \mathrm{SH}$ capacity of the ACOM sample, the area of the peak between $100{ }^{\circ} \mathrm{C}$ and $300{ }^{\circ} \mathrm{C}$ is the largest of the samples. There is no peak representing the removal of water. $\mathrm{CH}_{3} \mathrm{SSCH}_{3}$ was more easily adsorbed on the carbon surface than water. Therefore, water could be completely replaced, and the carbon surface would be covered by $\mathrm{CH}_{3} \mathrm{SSCH}_{3}$ when the content of $\mathrm{CH}_{3} \mathrm{SSCH}_{3}$ was high.
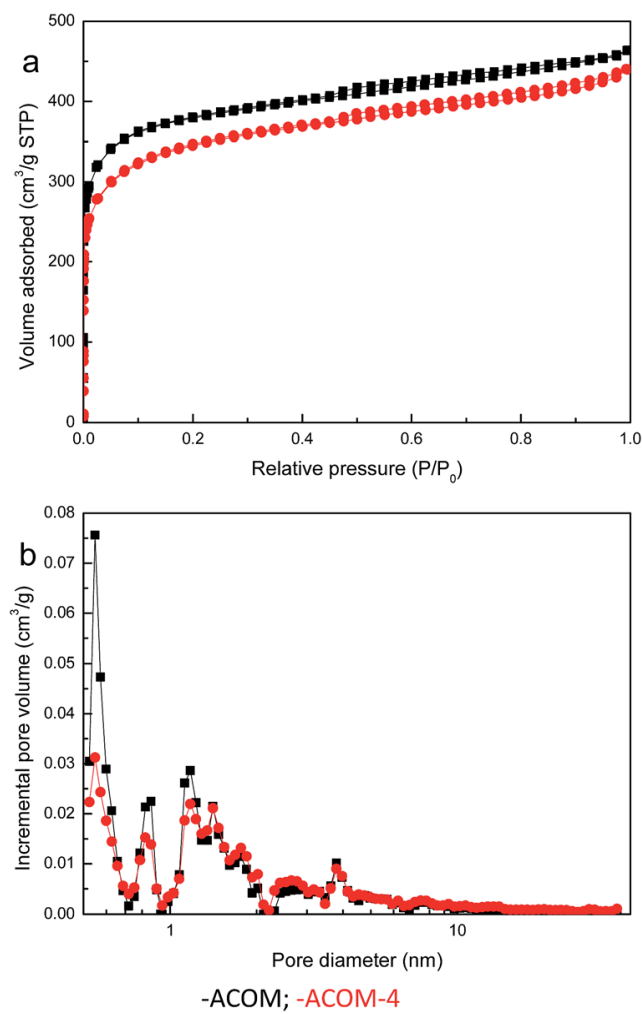

Fig. $9 \mathrm{~N}_{2}$ adsorption/desorption isotherms (a) and pore size distribution curves (b) of the samples. 


\subsection{Regeneration of the exhausted ACOME for $\mathrm{CH}_{3} \mathrm{SH}$ adsorption/oxidation}

As the main oxidation product of $\mathrm{CH}_{3} \mathrm{SH}, \mathrm{CH}_{3} \mathrm{SSCH}_{3}$ can be easily removed from the carbon surface. The exhausted activated carbon was regenerated through ethanol scrubbing and thermal treatment. As shown in Fig. 8, after four regeneration cycles, only a slight decrease in the $\mathrm{CH}_{3} \mathrm{SH}$ capacity of ACOM-4 was found, with a reserved $\mathrm{CH}_{3} \mathrm{SH}$ capacity of $88.33 \%$. The structure and chemical properties of fresh ACOM and regenerated ACOM- 4 were studied to explore the mechanism. The $\mathrm{N}_{2}$ adsorption isotherms and pore size distribution curves of ACOM and ACOM-4 are presented in Fig. 9, and the calculated structural parameters are summarized in Table 6. Similar isotherms are observed for the two samples. After four regeneration cycles, only a slight decrease in the pore volume of ACOM-4 occurred, especially in the micropore volume, which is confirmed by the pore size distribution curves. The XPS results for ACOM and ACOM-4 are shown in Fig. 10 and Table 7. The results indicate that the surface nitrogen content slightly decreases from 4.41 at $\%$ to 4.12 at\%. Specifically, there is a slight decrease in the relative contents of pyridinic nitrogen and quaternary nitrogen and a slight increase in the contents of

Table 6 Structural parameters of samples calculated from the nitrogen adsorption isotherms

\begin{tabular}{llllll}
\hline Sample & $\begin{array}{l}S_{\text {BET }} \\
\left(\mathrm{m}^{2} \mathrm{~g}^{-1}\right)\end{array}$ & $\begin{array}{l}V_{<1 \mathrm{~nm}} \\
\left(\mathrm{~cm}^{3} \mathrm{~g}^{-1}\right)\end{array}$ & $\begin{array}{l}V_{\text {mic }} \\
\left(\mathrm{cm}^{3} \mathrm{~g}^{-1}\right)\end{array}$ & $\begin{array}{l}V_{\mathrm{t}} \\
\left(\mathrm{cm}^{3} \mathrm{~g}^{-1}\right)\end{array}$ & $V_{\text {mic }} / V_{\mathrm{t}}$ \\
\hline ACOM & 1358 & 0.299 & 0.509 & 0.718 & 0.709 \\
ACOM-4 & 1261 & 0.247 & 0.456 & 0.681 & 0.670
\end{tabular}

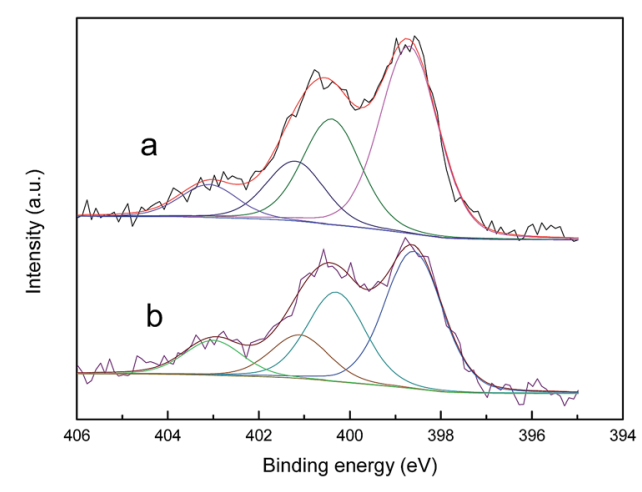

Fig. $10 \mathrm{~N}$ 1s XPS spectra of (a) ACOM, and (b) ACOM-4.

Table 7 Surface nitrogen contents and distribution of nitrogen species derived from the $\mathrm{N}$ 1s spectra

\begin{tabular}{lllllr}
\hline & & \multicolumn{4}{c}{ Distributions of nitrogen species (\%) } \\
\cline { 3 - 6 } Sample & $\begin{array}{l}\text { Nitrogen } \\
\text { content (at\%) }\end{array}$ & N-6 & N-5 & N-Q & N-X \\
\hline ACOM & 4.41 & 48.53 & 27.42 & 15.48 & 8.57 \\
ACOM-4 & 4.12 & 45.12 & 29.25 & 14.16 & 11.47
\end{tabular}

pyrrolic nitrogen and pyridine-N-oxide. The regeneration tests indicate that the pore structure is basically recovered and the active nitrogen domains are stable; thus, a good regeneration performance was observed.

\subsection{Possible reaction mechanism of $\mathrm{CH}_{3} \mathrm{SH}$ catalytic oxidation}

Active nitrogen sites play an important role in the adsorption/ oxidation of $\mathrm{CH}_{3} \mathrm{SH}$ based on the interaction between the $\mathrm{CH}_{3} \mathrm{SH}$ capacity and the contents of pyridinic nitrogen and quaternary nitrogen in the nitrogen-doped activated carbons. An overall mechanism is proposed to describe the $\mathrm{CH}_{3} \mathrm{SH}$ adsorption/oxidation process over the nitrogen-rich coconut shell activated carbon. A thin water film is formed on the carbon surface with the introduction of a moist gas. $\mathrm{CH}_{3} \mathrm{SH}$ molecules are adsorbed on the surface and dissolve into the water film, which can dissociate into protons and thiolate ions. Pyridinic nitrogen can act as a Lewis basic site with a lone electron pair. Thus, the presence of pyridinic nitrogen could promote the dissociation of $\mathrm{CH}_{3} \mathrm{SH}$ to thiolate ions. As suggested by Strelko, the extra electrons of pyridinic nitrogen and quaternary nitrogen occupy the high-energy states. ${ }^{47}$ The electrons could be transferred from the thiolate ion to the adsorbed oxygen, forming thiolate radicals and superoxide ions, because the two types of nitrogen groups enhance the ion-exchange properties of the carbons. These superoxide ions can react with water, forming hydroxyl radicals. All of these species could also facilitate oxidation. Finally, water and $\mathrm{CH}_{3} \mathrm{SSCH}_{3}$ are formed and stored in the pores. Considering the presence of water and active sites, such as hydroxyl radicals and oxygen radicals, $\mathrm{CH}_{3} \mathrm{SSCH}_{3}$ can be further oxidized into methyl methane thiosulfonate and methanesulfonic acid, as demonstrated by the DTG and GC/MS results. The oxidation process will proceed until all the pores with active nitrogen centers are filled with the oxidation products. The exhausted sample can be recovered by ethanol exaction and thermal regeneration. Despite the slight decrease in pore volume and nitrogen content, the $\mathrm{CH}_{3} \mathrm{SH}$ capacity can be maintained during the regeneration process.

\section{Conclusions}

In summary, a series of nitrogen-doped coconut shell activated carbons were prepared and used for the removal of $\mathrm{CH}_{3} \mathrm{SH}$. The results demonstrate that the $\mathrm{CH}_{3} \mathrm{SH}$ capacities of these modified activated carbons increase with the contents of nitrogen, especially pyridinic nitrogen and quaternary nitrogen. The unparalleled $\mathrm{CH}_{3} \mathrm{SH}$ capacity of the nitrogen-rich coconut shell activated carbon can be obtained when the nitrogen content is 4.41 at $\%$. The main product adsorbed on the carbon surface is $\mathrm{CH}_{3} \mathrm{SSCH}_{3}$, while some deeper oxidation products, such as methyl methane thiosulfonate and methanesulfonic acid, are also generated because of the strong oxidative ability of the nitrogen-rich coconut shell activated carbon. The exhausted nitrogen-rich carbons can be easily regenerated by ethanol scrubbing and thermal treatment, making them effective adsorbents of $\mathrm{CH}_{3} \mathrm{SH}$ in industrial fields. 


\section{Notes and references}

1 L. Ding, T. Liu and X. Li, J. Chem. Technol. Biotechnol., 2014, 89, 455-461.

2 M. C. Iliuta and F. Larachi, J. Chem. Eng. Data, 2007, 52, 2-19.

3 M. E. Whelan, D. Min and R. C. Rhew, Atmos. Environ., 2013, 73, 131-137.

4 T. Wu, X. Wang, D. Li and Z. Yi, Atmos. Environ., 2010, 44, 5065-5071.

5 C. Rhodes, S. A. Riddel, J. West, B. P. Williams and G. J. Hutchings, Catal. Today, 2000, 59, 443-464.

6 W. Cai, G. Lu, J. He and Y. Lan, Ceram. Int., 2009, 38, 31673174.

7 C. Cammarano, E. Huguet, R. Cadours, C. Leroi, B. Coq and V. Hulea, Appl. Catal., B, 2014, 156-157, 128-133.

8 M. G. Conti-Ramsden, K. Nkrumah-Amoako, N. W. Brown and E. P. L. Roberts, Adsorption, 2013, 19, 989-996.

9 E. Huguet, B. Coq, R. Durand, C. Leroi, R. Cadours and V. Hulea, Appl. Catal., B, 2013, 134-135, 344-348.

10 R. C. van Leerdam, P. L. F. van den Bosch, P. N. L. Lens and A. J. H. Janssen, Environ. Sci. Technol., 2011, 45, 1320-1326.

11 A. Bagreev, J. A. Menendez, I. Dukhno, Y. Tarasenko and T. J. Bandosz, Carbon, 2005, 43, 208-210.

12 S. Bashkova, A. Bagreev and T. J. Bandosz, Environ. Sci. Technol., 2002, 36, 2777-2782.

13 H. Cui and S. Q. Turn, Appl. Catal., B, 2009, 88, 25-31.

14 S. Bashkova, A. Bagreev and T. J. Bandosz, Langmuir, 2003, 19, 6115-6121.

15 E. Vega, J. Lemus, A. Anfruns, R. Gonzalez-Olmos, J. Palomar and M. J. Martin, J. Hazard. Mater., 2013, 258-259, 77-83.

16 D. J. Kim and J. E. Yie, J. Colloid Interface Sci., 2005, 283, 311315.

17 S. Lee, W. M. A. W. Daud and M. Lee, J. Ind. Eng. Chem., 2010, 16, 973-977.

18 H. Tamai, H. Nagoya and T. Shiono, J. Colloid Interface Sci., 2006, 300, 814-817.

19 S. Zhao, H. Yi, X. Tang, F. Gao, B. Zhang, Z. Wang and Y. Zuo, J. Cleaner Prod., 2015, 87, 856-861.

20 H. Zhong, H. Zhang, S. Liu, C. Deng and M. Wang, ChemSusChem, 2013, 6, 807-812.

21 N. Yan and X. Chen, Nature, 2015, 524, 155-157.

22 T. Nguyen, K. E. Shopsowitz and M. J. MacLachlan, J. Mater. Chem. A, 2014, 2, 5915-5921.

23 X. Chen, H. Yang and N. Yan, Chem.-Eur. J., 2016, 22, 1340213421.
24 S. Bashkova and T. J. Bandosz, J. Colloid Interface Sci., 2009, 333, 97-103.

25 F. Sun, J. Liu, H. Chen, Z. Zhang, W. Qiao, D. Long and L. Ling, ACS Catal., 2013, 3, 862-870.

26 J. Jagiello and J. P. Olivier, Carbon, 2013, 55, 70-80.

27 J. Jagiello, C. Ania, J. B. Parra and C. Cook, Carbon, 2015, 91, 330-337.

28 X. Liu, J. Guo, Y. Chu, D. Luo, H. Yin, M. Sun and Y. Reha, Fuel, 2014, 123, 93-100.

29 G. Zhang, Z. Li, H. Zheng, T. Fu, Y. Ju and Y. Wang, Appl. Catal., B, 2015, 179, 95-105.

30 H. Shamsijazeyi and T. Kaghazchi, J. Ind. Eng. Chem., 2010, 16, 852-858.

31 M. Seredych, D. Hulicova-Jurcakova, G. Lu and T. J. Bandosz, Carbon, 2008, 46, 1475-1488.

32 A. Bagreev, J. Angel Menendez, I. Dukhno, Y. Tarasenko and T. J. Bandosz, Carbon, 2004, 42, 469-476.

33 X. Lu, J. Jiang, K. Sun, X. Xie and Y. Hu, Appl. Surf. Sci., 2012, 258, 8247-8252.

34 J. Chen, Y. Zhai, H. Chen, C. Li, G. Zeng, D. Pang and P. Lu, Appl. Surf. Sci., 2012, 263, 247-253.

35 L. Li, S. Liu and J. Liu, J. Hazard. Mater., 2011, 192, 683-690. 36 H. P. Boehm, Adv. Catal., 1966, 16, 179-274.

37 M. A. Nahil and P. T. Williams, J. Chem. Eng., 2012, 184, 228237.

38 H. Xiong, M. A. Motchelaho, Z. N. Tetana, S. M. A Dube, L. L. Jewell and N. J. Coville, J. Catal., 2014, 311, 80-87.

39 A. Nieto-Márquez, D. Toledano, P. Sánchez, A. Romero and J. L. Valverde, J. Catal., 2010, 269, 242-251.

40 L. Lin, Q. Zhu and A. W. Xu, J. Am. Chem. Soc., 2014, 136, 11027-11033.

41 J. Han, S. Lee, K. Choi, J. Kim, D. Ha, C. G. Lee, B. An, S. H. Lee, H. Mizuseki, J. W. Choi and S. Kang, J. Hazard. Mater., 2016, 302, 375-385.

42 Y. Gao, X. Chen, J. Zhang and N. Yan, ChemPlusChem, 2015, 80, 1556-1564.

43 S. Bashkova, A. Bagreev and T. J. Bandosz, Catal. Today, 2005, 99, 323-328.

44 S. Bashkova, A. Bagreev and T. J. Bandosz, Ind. Eng. Chem. Res., 2002, 41, 4346-4352.

45 F. Adib, A. Bagreev and T. J. Bandosz, J. Colloid Interface Sci., 1999, 214, 407-415.

46 F. Adib, A. Bagreev and T. J. Bandosz, Environ. Sci. Technol., 2000, 34, 686-692.

47 V. V. Strelko, V. S. Kuts and P. A. Thrower, Carbon, 2000, 38, 1499-1503. 